\title{
Identification of an Agent in Cultures of Aspergillus fumigatus Displaying Anti-phagocytic and Immunomodulating Activity in vitro
}

\author{
By ARNO MÜLLBACHER, 1* PAUL WARING ${ }^{2}$ AND \\ RONALD D. EICHNER ${ }^{3}$ \\ Departments of Microbiology ${ }^{1}$, Biochemistry ${ }^{2}$ and Immunology ${ }^{3}$, John Curtin School of Medical \\ Research, Australian National University, Canberra, ACT 2601, Australia
}

(Received 30 November 1984)

\begin{abstract}
When cultured in vitro, Aspergillus fumigatus generated a metabolite(s) with anti-phagocytic activity as tested by macrophage adherence to plastic and phagocytosis of particulate matter. The metabolite(s) appeared after $3 \mathrm{~d}$ culture and reached a peak concentration after 5-6 d. The action of the anti-phagocytic agent(s) was rapid (5-15 $\mathrm{min}$ ) and appeared not to alter membrane permeability or cause rapid cell death. Treatment of stimulator spleen cells with the agent(s) inhibited their ability to induce alloreactive and major histocompatibility complex restricted cytotoxic $\mathrm{T}$ cells. The metabolite(s) was chloroform-soluble and separated into three biologically active compounds on thin-layer chromatography. These compounds were purified $>1000$-fold and one of them was identified as gliotoxin, a known metabolite of $A$. fumigatus, based upon NMR and IR spectroscopy, mass spectrometry, biological properties and other data.
\end{abstract}

\section{INTRODUCTION}

Aspergillus fumigatus, a widely distributed saprophytic and thermophytic fungus of the order Eurotiales, is a common pathogen to animals and man (Howard, 1983). In concordance with its habitat on decaying organic matter is its ability to synthesize a number of anti-microbial metabolites and digestive enzymes (Raper \& Fennell, 1965). Many of the anti-microbial substances synthesized by the fungus, such as fumigatin, helvolic acid, fumagillin and gliotoxin, have been investigated for their potential as anti-bacterial, anti-fungal, anti-viral and ameobicidal drugs (McCowen et al., 1951; Taylor, 1971; Wilson, 1971). However, their application in vivo has been greatly curtailed by high cellular toxicity in mammals.

Renewed interest in fungal metabolites has been generated by the discovery of the immunoregulatory agent cyclosporin A, a fungal metabolite of Tolypocladium inflatum Gams (Borel et al., 1976). Cyclosporin A has proved to be an invaluable tool both in the investigation of the basic principles of immune induction and immune regulation (Borel \& Lafferty, 1983), and in therapeutic application in the field of tissue transplantation (Starzl, 1983).

We report here the fortuitous discovery of a metabolite(s) of $A$. fumigatus with anti-phagocytic and immunomodulating properties and its identification as gliotoxin.

\section{METHODS}

Mice. CBA/H and C57BL/10 strains were bred at the John Curtin School of Medical Research. They were used at 6-12 weeks of age.

Preparation of Aspergillus fumigatus culture supernatant $(S A F)$. Conidiospores, taken from agar slopes previously inoculated with $A$. fumigatus and stored at $4{ }^{\circ} \mathrm{C}$, were suspended in Eagle's minimal essential medium F15 (Grand

Ahbreriations: SAF, Aspergillus fumigatus culture supernatant; TGM, thioglycollate-induced peritoneal macrophages: $\mathrm{MHC}$, major histocompatibility complex. 
Island Biological Co., Grand Island, NY, USA) and cultured without agitation for 5-6 d at $37^{\circ} \mathrm{C}$ in a humidified $5 \%(\mathrm{v} / \mathrm{v}) \mathrm{CO}_{2}$ atmosphere. The fungal mycelium was removed by passing the culture medium through a nylon mesh, and the culture fluid was sterilized by filtration (Millex-GS $0.22 \mu \mathrm{m}$, Millipore SA, Molsheim, France) and stored at $-20{ }^{\circ} \mathrm{C}$.

Fungal metabolites. Gliotoxin was a generous gift of Dr R. Gallagher of the Ruakura Animal Research Station, Hamilton, New Zealand, and Dr A. Taylor, Atlantic Research Laboratory, Halifax, Canada; helvolic acid was provided by Smith, Kline and French, Sydney, NSW, Australia, and fumagillin by Merck, Sharpe and Dome, Rahway, NY, USA. These substances were dissolved in absolute ethanol at $1 \mathrm{mg} \mathrm{ml}^{-1}$ and stored at $-70^{\circ} \mathrm{C}$. Cytochalasin B (Sigma) was dissolved in dimethylsulphoxide and stored at $4{ }^{\circ} \mathrm{C}$. All compounds were appropriately diluted in F15 prior to use.

Cells. Thioglycollate-induced peritoneal macrophages (TGM) were harvested from thioglycollate-injected mice [intraperitoneal (i.p.) injection of $2 \mathrm{ml} \mathrm{3 \% (w/v)} \mathrm{thioglycollate} \mathrm{(Difco)} \mathrm{solution} \mathrm{5-8} \mathrm{d} \mathrm{previously]} \mathrm{by} \mathrm{the} \mathrm{i.p.}$ injection of $7 \mathrm{ml}$ ice-cold Puck's saline and withdrawal of the saline with a syringe and 20-gauge needle. TGM were then sedimented by centrifugation and resuspended in F15 plus $5 \%(\mathrm{v} / \mathrm{v})$ foetal calf serum.

The mouse tumour cell line L929 and secondary mouse embryo fibroblasts were grown in Dulbecco's modified Eagle's medium H16 (Grand Island Biological Co.) containing 6\% foetal calf serum.

Neutral red cell adherence assay. The method has been described in detail elsewhere (Müllbacher \& Eichner, 1984). In brief, $5 \times 10^{6}-5 \times 10^{7} \mathrm{TGM}, \mathrm{L} 929$ or fibroblasts were labelled in suspension for $15 \mathrm{~min}$ at $37^{\circ} \mathrm{C}$ in $5 \mathrm{ml}$ $0.04 \%(w / v)$ neutral red $(\mathrm{Cl} 50040, \mathrm{BDH})$ in Hanks' balanced salt solution. The cells were sedimented, washed twice in F15 containing $1 \%$ foetal calf serum and resuspended at $5 \times 10^{5}$ cells ml $^{-1}$. Samples $(0.1 \mathrm{ml})$ were distributed in each well of a 96-well round-bottom tissue culture plate (cat. no. 76-013-05; Linbro Division, Flow Laboratories). The plates initially contained $0.1 \mathrm{ml}$ samples of SAF or dilutions thereof prior to the addition of neutral-red-labelled cells. After an appropriate incubation at $37^{\circ} \mathrm{C}$, the medium was thrown off and the cell monolayers were washed by immersing the microplate once in a phosphate-buffered saline (PBS) (0.143 $\mathrm{M}$-sodium chloride, 0.01 M-sodium phosphate, $\mathrm{pH} 7.4$ ) bath. The PBS was thrown off and the neutral red was released from the remaining adherent cells by addition of $0.1 \mathrm{ml}$ per well of $0.05 \mathrm{M}$-acetic acid in $50 \%(\mathrm{v} / \mathrm{v})$ ethanol, whereupon absorbance at $540 \mathrm{~nm}$ was measured by a microplate reader (Dynatech 600).

Generation and cytotoxicity testing of alloreactive and $M H C$-restricted cytotoxic $T$ cells. The methods have been described in detail elsewhere (Müllbacher et al., 1984). In brief, female C57BL/10 mice were immunized with 10 ${ }^{7}$ syngeneic male spleen cells i.p. and used after a minimum of 4 weeks post-priming. To generate alloreactive and major histocompatibility complex $(\mathrm{MHC})$ restricted cytotoxic $\mathrm{T}$ cells, $10^{7}$ spleen responder cells from previously immunized animals were co-cultured with $4 \times 10^{6} \mathrm{CBA} / \mathrm{H}$ or $5 \times 10^{6}$ male C57BL/10 irradiated (2000 R from a ${ }^{60} \mathrm{Co}$ source) spleen stimulator cells respectively. The cells were incubated in $5 \mathrm{ml} \mathrm{F} 15$ containing $5 \%$ foetal calf serum plus $10^{-4} \mathrm{M}-2$-mercaptoethanol in 12-well culture dishes (Costar, Cambridge, Mass., USA) for $5 \mathrm{~d}$ at $37^{\circ} \mathrm{C}$ in a humidified $5 \% \mathrm{CO}_{2}$ atmosphere.

The cultures were harvested and $0.1 \mathrm{ml}$ samples of cells were titrated in three-fold dilution steps into 96 -well round-bottom tissue culture plates. TGM target cells were labelled with ${ }^{51} \mathrm{Cr}$ (Amersham) for $1 \mathrm{~h}$, washed thoroughly and added in $0.1 \mathrm{ml}$ portions at $2 \times 10^{5}$ cells ml $\mathrm{m}^{-1}$ and incubated at $37^{\circ} \mathrm{C}$ for $6 \mathrm{~h}$. Then $0 \cdot 1 \mathrm{ml}$ volumes of individual well supernatants were removed and radioactivity was measured in a gamma-counter. Medium release was estimated by culturing target cells in the absence of effector cells. Total releasable ${ }^{51} \mathrm{Cr}$ was estimated by lysing target cells with $1 \%$ Triton-X solution. Percentage specific lysis was calculated as: [(experimental release - medium release $) /($ maximum release - medium release $)] \times 100$.

Isolation and purification of biologically active metabolites. One to five litres of SAF was obtained as described above and freed of mycelium by filtration through multiple layers of gauze, followed by filtration through paper (Whatman no. 540). The resulting solution was extracted three times with chloroform ( $50-250 \mathrm{ml})$, then dried over sodium sulphate and finally evaporated (reduced pressure at $35-40^{\circ} \mathrm{C}$ ) to dryness. The aqueous layer, which contained less than $1-2 \%$ of the biological activity, was discarded. The crude material was examined using thinlayer chromatography (TLC) (Merck silica plates, $5 \times 10 \mathrm{~cm} ; 0.5 \mathrm{~mm}$ thickness), developed in dichloromethane/ methanol $(95: 5, \mathrm{v} / \mathrm{v})$ and visualized under UV light.

The material was applied to a preparative silica plate (Merck, $20 \times 20 \mathrm{~cm} ; 2 \mathrm{~mm}$ thickness) and developed in dichloromethane/methanol $(95: 5, \mathrm{v} / \mathrm{v})$. The active bands were individually removed, crushed in a mortar and then extracted with acetone $(3 \times 30 \mathrm{ml})$. The acetone was filtered and evaporated. The product was dried at $20^{\circ} \mathrm{C}$ under vacuum for $2 \mathrm{~h}$ and then taken up in a small volume of chloroform and recrystallized upon addition of cyclohexane. The solid was collected by centrifugation and then dried as above.

Spectroscopic studies of purified SAF metabolites. Proton NMR spectroscopy was performed on a JEOL FX90Q spectrometer operating at $89.56 \mathrm{MHz}$ at $37^{\circ} \mathrm{C}$. Chemical shifts were measured in p.p.m. downfield from added trimethylsilane. IR spectra were run in $\mathrm{KBr}$ on a Unicam SP1000 spectrometer. Mass spectra were run on an MS-9 spectrometer.

Calculation of biological activity. The absorbance at $540 \mathrm{~nm}$, indicative of the residual adherent neutral-redlabelled TGM population, was plotted against the dilution of SAF; similar plots were constructed as a function of 


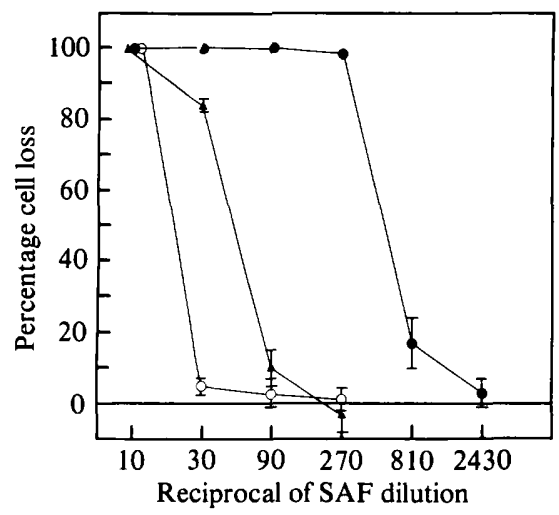

Fig. 1. Cell adherence to plastic in the presence of SAF. Samples of $5 \times 10^{4}$ neutral-red-labelled L929 cells $(O)$, secondary fibroblasts $(\Delta)$, or mouse TGM $(O)$ were added to microtitre wells containing SAF at dilutions of $1 / 10$ to $1 / 2430$. Cell adherence after $5 \mathrm{~h}$ was measured as absorbance at $540 \mathrm{~nm}$ as detailed in Methods. The vertical bars represent SEM; where no bar is shown the plotted SEM was $\leqslant$ the size of the symbol.

concentration for known or identified substances. The effective dilution of SAF is defined as that dilution which results in $50 \%$ of the maximum observed loss of adherent TGM; the corresponding parameter for purified fractions of known compounds is expressed as the $\mathrm{ED}_{50}$ or effective dose. The amount of biological activity in culture or purified fractions is determined by the following formula: [(ED 50 or effective dilution)/(ED ${ }_{50}$ for authentic gliotoxin) $] \times$ [gliotoxin $]_{\mathrm{Std}}$, where [gliotoxin $]_{\mathrm{Std}_{\mathrm{d}}}$ is the concentration of an authentic gliotoxin solution (usually $1-10 \mu \mathrm{g} \mathrm{ml}^{-1}$ ). An additional dilution factor was applied when analysing concentrated chloroform extracts.

\section{RESULTS}

Inhibition of cell adherence in the presence of $A$. fumigatus culture supernatants

During a routine immunological assay for cytotoxic $\mathrm{T}$ lymphocytes using the neutral red colorimetric assay system (Müllbacher et al., 1984), we observed that lymphocyte effector cells recovered from an in vitro mixed lymphocyte culture contaminated by Aspergillus fumigatus caused TGM target cells to lose their ability to adhere to plastic.

To answer the question whether a fungal metabolite was responsible for the loss of TGM adherence to plastic and whether the activity is specific for TGM, especially as it is known that macrophages adhere to plastic by a process akin to phagocytosis (Grinnel, 1978), different cell types (L929, secondary fibroblasts and TGM) were tested for their sensitivity to SAF using the neutral red adherence test (Fig. 1). L929 and secondary fibroblasts did not adhere to plastic at the highest concentrations of SAF, but their adherence was not inhibited at lower concentrations. However, dilutions of SAF of up to $1 / 810$ inhibited TGM adherence to plastic. Loss of adherence to plastic was rapid after addition of SAF to adherent neutral-red-stained TGM: an incubation period of $20 \mathrm{~min}$ was usually sufficient to completely reverse adherence, and up to $50 \%$ of cells were lost after as short a period as 5-10 min (data not shown).

To ascertain whether the SAF-induced loss of adherence by TGM was correlated with loss of phagocytosis, TGM were treated with SAF at various dilutions for $1 \mathrm{~h}$, washed thoroughly and incubated with India ink $(3 \%, v / v)$ in cell culture medium for a further $1 \mathrm{~h}$. The cells were separated from free carbon particles by differential centrifugation and observed by light microscopy. Control TGM contained large amounts of phagocytosed carbon particles, (Fig. 2a), whereas TGM treated with SAF were devoid of carbon inclusions (Fig. 2b;1/90 dilution). Internalization of the particulate matter was confirmed by electron microscopy (not shown). However, no change in cell viability was observed with TGM up to $48 \mathrm{~h}$ after treatment with SAF; membrane permeability and metabolic activity, as tested by neutral red and ${ }^{51} \mathrm{Cr}$ uptake and spontaneous release, appeared not to be affected over a $24 \mathrm{~h}$ period after SAF treatment (unpublished observation). 

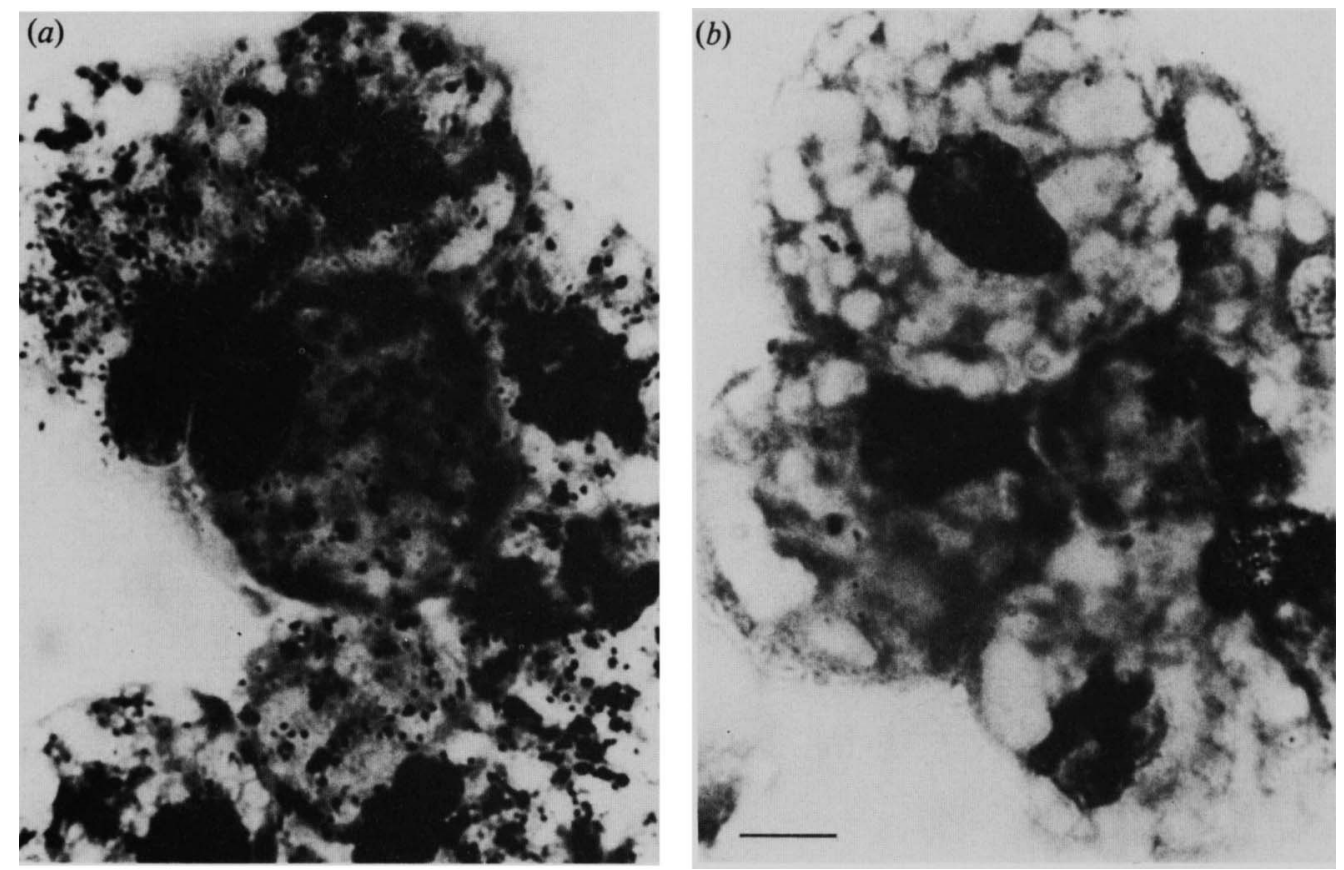

Fig. 2. Phagocytosis by TGM of carbon particles in the presence or absence of SAF. TGM were left untreated (control, $a$ ) or treated for $1 \mathrm{~h}$ with a $1 / 90$ dilution of $\operatorname{SAF}(b)$, then exposed to India ink $(3 \%$, $\mathrm{v} / \mathrm{v}$ ) for $1 \mathrm{~h}$, and examined by light microscopy. Bar, $10 \mu \mathrm{m}$ (magnification the same in $a$ and $b$ ).

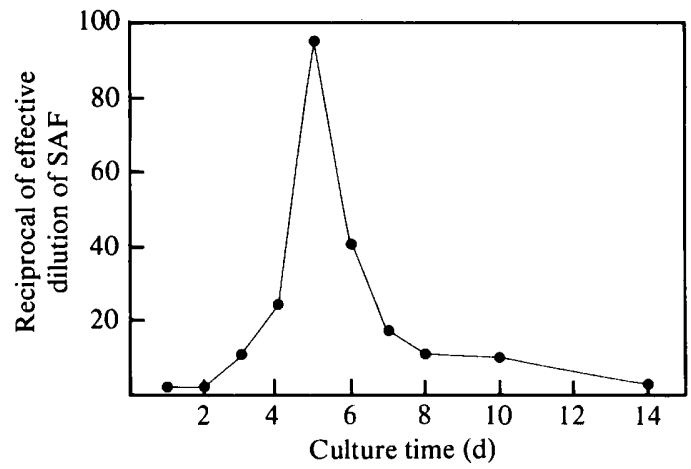

Fig. 3. Kinetics of production of anti-phagocytic metabolite(s) by A. fumigatus in vitro. Samples of $1 \mathrm{ml}$ of an $A$. fumigatus culture were removed daily, sterilized by membrane filtration and frozen. All samples were tested for their ability to inhibit macrophage adherence to plastic. The effective dilution of the individual samples (that dilution which results in $50 \%$ of the maximum inhibition of adherence of neutral-red-labelled TGM) was determined and is shown as a function of duration of culture.

\section{Kinetics of production of anti-phagocytic metabolite(s)}

Long-term culture supernatants of $\boldsymbol{A}$. fumigatus showed less anti-phagocytic activity than supernatants from short-term cultures. It was therefore important to establish the kinetics of synthesis of the factor(s) responsible for the inhibition of TGM adherence. A conidiospore suspension (about $10^{8}$ spores per $40 \mathrm{ml}$ medium) in $\mathrm{F} 15$ plus $5 \%$ foetal calf serum was set up and $1 \mathrm{ml}$ samples were harvested daily for $14 \mathrm{~d}$, filter-sterilized and stored at $-20^{\circ} \mathrm{C}$. All samples were assayed at the same time for their ability to prevent adherence of neutral-red-stained TGM (Fig. 3). Activity first appeared at day 3, reached a peak at day 5 and declined progressively thereafter. Maximum levels of activity varied between experiments, although the kinetics of production remained constant. 
Table 1. Effect of SAF on stimulator cells in alloreactive and MHC-restricted Tc cell induction

\begin{tabular}{|c|c|c|c|c|c|}
\hline \multirow[b]{2}{*}{ Effector $T$ cells } & \multirow[b]{2}{*}{$\begin{array}{l}\text { Treatment of } \\
\text { stimulators }\end{array}$} & \multirow[b]{2}{*}{$\begin{array}{l}\text { Yield of } \\
\text { responder } \\
\text { cells* }\end{array}$} & \multicolumn{3}{|c|}{$\begin{array}{l}\text { Percentage specific }{ }^{51} \mathrm{Cr} \text { release } \\
\text { from macrophage target cells } \dagger\end{array}$} \\
\hline & & & $\begin{array}{c}\text { B } 10 \\
\text { female }\end{array}$ & $\begin{array}{l}\text { B } 10 \\
\text { male }\end{array}$ & $\begin{array}{c}\text { CBA } \\
\text { female }\end{array}$ \\
\hline $\mathrm{C} 57 \mathrm{BL} / 10$ anti-CBA/H & $\begin{array}{l}\text { Nil } \\
\text { SAF }\end{array}$ & $\begin{array}{l}45 \\
40\end{array}$ & $\begin{array}{l}0(2 \cdot 4) \\
0(2 \cdot 8)\end{array}$ & $\begin{array}{l}\text { NT } \\
\text { NT }\end{array}$ & $\begin{aligned} 49.0(2 \cdot 6) \\
0(1 \cdot 1)\end{aligned}$ \\
\hline $\begin{array}{l}\text { C57BL/10 female } \\
\text { anti-C57BL/10 male }\end{array}$ & $\begin{array}{l}\text { Nil } \\
\text { SAF }\end{array}$ & $\begin{array}{l}47 \\
36\end{array}$ & $\begin{array}{l}0(5 \cdot 5) \\
0(4 \cdot 5)\end{array}$ & $\begin{array}{r}65 \cdot 4(0 \cdot 8) \\
0(4 \cdot 2)\end{array}$ & $\begin{array}{l}\text { NT } \\
\text { NT }\end{array}$ \\
\hline
\end{tabular}

\section{Effect of SAF on the induction of alloreactive and MHC-restricted cytotoxic $T$ cells}

As it is well established that macrophages and/or macrophage-like cells are a necessary accessory cell for the induction of cytotoxic $T$ cell responses in vitro, it was of interest to investigate the effect of SAF on stimulator cell populations in mixed lymphocyte cultures. $\mathrm{CBA} / \mathrm{H}$ and male C57BL/10 spleen stimulator cells were each incubated with SAF for $1 \mathrm{~h}$ or left untreated. The stimulators were washed twice and then each co-cultured with male-primed C57BL/10 female spleen cells for $5 \mathrm{~d}$, as described in Methods.

Samples of the alloreactive $\mathrm{C} 57 \mathrm{BL} / 10$ anti-CBA/H cultures were tested on $\mathrm{CBA} / \mathrm{H}$ and C57BL/10 targets and the MHC-restricted C57BL/10 anti-male effectors were tested on C57BL/10 male and female macrophage targets. (Table 1). SAF-treated stimulator cells were unable to induce a cytotoxic $T$ cell response either in the allogeneic combination $(\mathrm{C} 57 \mathrm{BL} / 10$ anti-CBA/H) or in the syngeneic MHC-restricted anti-male response (C57BL/10 female antiC57BL/10 male).

\section{Purification of A. fumigatus metabolites}

The biologically active components of SAF were purified over 1000 -fold by chloroform extraction, TLC and recrystallization (Table 2). Three active components, A, B and C (Fig. 4) with comparable specific activities were isolated in high yield. Components appearing above or below $\mathrm{A}, \mathrm{B}$ and $\mathrm{C}$ were ineffective in the TGM adherence assay.

\section{Identification of gliotoxin in $S A F$}

Preliminary studies indicated that the activity present in SAF had the following properties: (1) molecular weight less than 500 as determined by gel filtration; (2) stable to digestion with trypsin, protease and glycosidase; (3) unstable to heating in weak alkali, decomposing with the concomitant release of sulphide as measured by the lead acetate test.

The $R_{F}$ values for the biologically active components A, B and C (Fig. 4) were $0.49,0.41$ and $0 \cdot 34$, respectively; the $R_{F}$ value for purified authentic gliotoxin was 0.50 . Fig. 5 illustrates the NMR spectra for both authentic gliotoxin and component $A$. The following frequencies in $\mathrm{cm}^{-1}$ represent the peaks observed in the IR spectrum of component $A: 3450(\mathrm{~m}), 2930(\mathrm{w}), 1670(\mathrm{~s})$, $1460(w), 1380(w), 1280(w), 1240(w), 1200(w), 1060(w), 720(w), 710(w), 660(w)$ and $640(w)$ where $\mathrm{s}, \mathrm{m}$ and $\mathrm{w}$ refer to strong, medium or weak absorbances. A sample of authentic gliotoxin had an identical IR spectrum.

Three known metabolites of $A$. fumigatus, gliotoxin, helvolic acid and fumagillin, as well as cytochalasin B (a fungal metabolite affecting cell motility; Yahara et al., 1982) were tested for their ability to inhibit TGM adherence. The $\mathrm{ED}_{50}$ values (see Methods) of the compounds were: gliotoxin, $44 \mathrm{ng} \mathrm{ml}^{-1}$; helvolic acid, $>1.3 \mathrm{mg} \mathrm{ml}^{-1}$; fumagillin, $>0.5 \mathrm{mg} \mathrm{ml}^{-1}$; and cytochala$\sin \mathrm{B},>5 \mathrm{mg} \mathrm{ml}^{-1}$. Thus gliotoxin was the only active compound. 


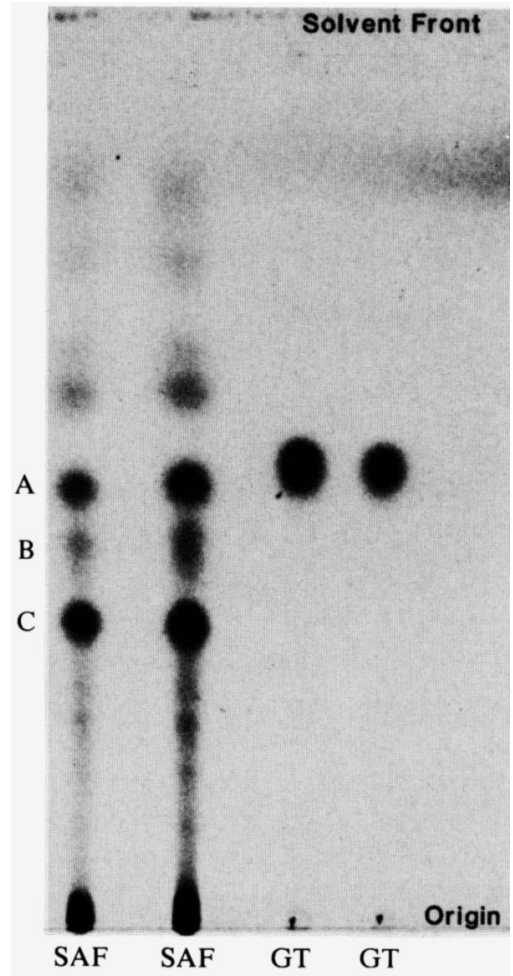

Fig. 4. Thin-layer chromatography of chloroform-extracted SAF and authentic gliotoxin (GT). Samples (about $5 \mu \mathrm{l}$ ) dissolved in chloroform were spotted on analytical TLC plates and developed in dichloromethane/methanol $(95: 5, \mathrm{v} / \mathrm{v})$. The plates were then examined under UV light.

Table 2. Purification of biologically active components of $S A F$

\begin{tabular}{lcccc}
\multicolumn{1}{c}{ Step } & $\begin{array}{c}\text { Activity } \\
\left(\mathrm{mg} \mathrm{l}^{-1}\right)\end{array}$ & $\begin{array}{c}\text { Recovery } \\
(\%)\end{array}$ & $\begin{array}{c}\text { Specific } \\
\text { activity }\end{array}$ & $\begin{array}{c}\text { Fold } \\
\text { purification }\end{array}$ \\
SAF & 12.0 & 100 & 0.0007 & 1 \\
Chloroform extraction & 10.6 & 88 & 0.16 & 230 \\
TLC & 7.4 & 62 & 0.76 & 1100 \\
Recrystallization $\ddagger$ & & & & \\
Component A & 2.1 & & $0.95 \pm 21 \%$ & \\
Component B & 1.6 & & $0.6 \pm 29 \%$ & \\
Component C & 3.7 & & $0.7 \pm 22 \%$ &
\end{tabular}

* Expressed as the ratio of the effective dilution or $\mathrm{ED}_{50}$ value in the TGM adherence assay relative to that value for authentic gliotoxin; the ratio was then multiplied by the concentration of the non-diluted gliotoxin standard solution.

$\uparrow$ Activity divided by the weight of non-volatile components. The values for components $\mathrm{A}, \mathrm{B}$ and $\mathrm{C}$ are given \pm coefficient of variation as compared to authentic gliotoxin.

$\ddagger$ Individual biologically active components (A, B and C in Fig. 4) were removed from TLC plates and recrystallized from chloroform/cyclohexane.

\section{DISCUSSION}

We have shown here that culture supernatants of $A$. fumigatus (SAF) contain an agent(s) which has anti-phagocytic properties, as evidenced by its inhibition of the ability of TGM to adhere to plastic surfaces (Grinnel, 1978). This inhibition was correlated with the lack of phagocytosis by TGM of carbon particles. It is not surprising to find that a saprophyte such as A. fumigatus produces a metabolite(s) with anti-phagocytic properties, considering the number of micro-organisms likely to occur in its habitat which rely on a phagocytic mechanism for nutrient intake. 


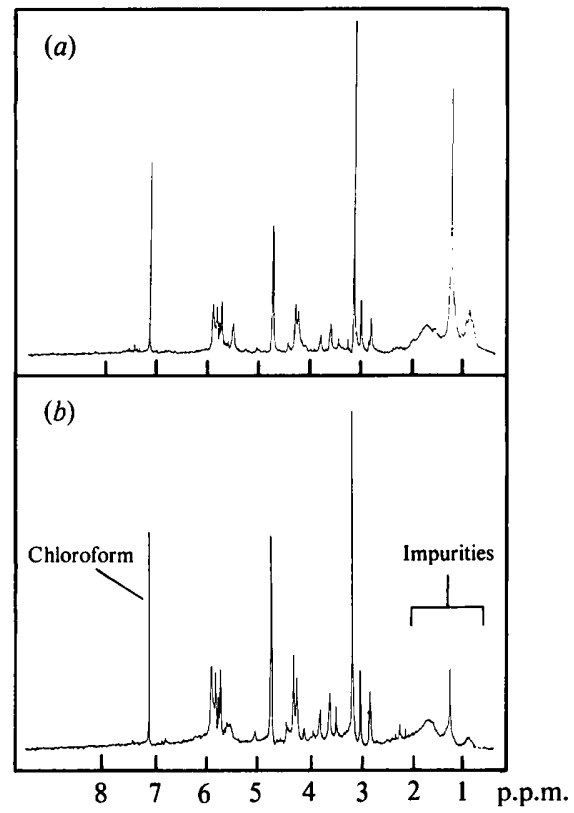

Fig. 5. NMR spectra of component A $(a)$ and authentic gliotoxin (b). Both spectra were taken on a JEOL FX90Q instrument operating at $89.56 \mathrm{MHz}$ at $37^{\circ} \mathrm{C}$. The solvent was deuterated chloroform. Chemical shifts (p.p.m.) were measured downfield from trimethylsilane.

In agreement with the anti-phagocytic effect was the observation that stimulator spleen cells treated with SAF lost their ability to induce an alloreactive or MHC-restricted cytotoxic $\mathrm{T}$ cell response. It is well established that (a) macrophages are an indispensable accessory cell in the in vitro generation of cytotoxic $T$ cells (Pang \& Blanden, 1976), and (b) a macrophage or macrophage-like cell is involved in antigen presentation and thus required for the induction of a cytotoxic $\mathrm{T}$ cell response (Persson et al., 1978).

The active compounds(s) appeared within 2-3 d of in vitro culture and maximum levels were reached after 5-6 d. The subsequent decline in activity may have been due to catabolism, to instability of the compounds under culture conditions, or perhaps to the production of an antagonist late in culture.

Inhibition of phagocytosis was rapid (5-15 min) but the mode of action of SAF is at present not understood. The observation that cytochalasin B did not prevent macrophage adherence suggests that the active metabolite in SAF does not interact with microfilaments. Apparently little alteration in membrane function and permeability occurred, as indicated by neutral red uptake and spontaneous ${ }^{51} \mathrm{Cr}$ release, both of which are metabolically active processes. Furthermore, cell viability was not affected for at least $48 \mathrm{~h}$ after the cells had been treated with $\mathrm{SAF}$; in addition, viable lymphocytes have been repeatedly recovered from mixed lymphocyte cultures contaminated by $\boldsymbol{A}$. fumigatus, thus ruling out a more generalized cell toxicity.

Our preliminary results rule out proteinaceous and/or high molecular weight substances as the biologically active components in SAF. SAF contains three chloroform-soluble biologically active materials with qualitatively and quantitatively similar activities to gliotoxin. The similarities between component $\mathrm{A}$ and gliotoxin include the following: (1) identical IR and NMR spectra; (2) the presence of the molecular ion $m / e=326$ and that corresponding to the loss of two sulphur atoms, $m / e=262$ (data not shown) (Bose et al., 1968); and (3) mobility on TLC (Taylor, 1971). Furthermore, of three $A$. fumigatus-derived compounds tested, helvolic acid, fumagillin and gliotoxin, only gliotoxin showed anti-phagocytic activity. We have since shown that gliotoxin also inhibits the generation of alloreactive cytotoxic $\mathrm{T}$ cells when stimulator cells are treated with gliotoxin (Müllbacher \& Eichner, 1984), an effect similar to what we have shown with SAF. Thus, our data confirm the identity of component $\mathrm{A}$ as gliotoxin. 
The identity of components B and C is not known. However, it is likely that they share some structural features with gliotoxin, since they share the following properties with it: (1) similar specific activity in the TGM adherence assay; (2) instability to heating in dilute alkali; (3) low molecular weight; (4) non-proteinaceous nature; (5) solubility in chloroform; and (6) similar mobility in several solvent systems on TLC. In fact, components A and B co-chromatograph on TLC when developed in ethyl acetate.

In conclusion, $\boldsymbol{A}$. fumigatus in in vitro culture produces gliotoxin and related immunomodulating agents. $A$. fumigatus is a common pathogen in humans and animals, but it remains to be seen to what extent gliotoxin is involved in making it the cause of a disease with poor prognosis for recovery (Rippon, 1974; Eichner \& Müllbacher, 1984).

We wish to thank J. P. Mundy and M. Cahill for excellent technical assistance, P. Douglas and D. Frey for identification of the organism and L. Hardy for typing the manuscript.

\section{REFERENCES}

Borel, J. F. \& LafFerty, K. J. (1983). Basic science summation. Transplantation Proceedings XI, 30973102.

Borel, J. F., Feurer, C., Gubler, H. U. \& Stähelin, H. (1976). Biological effects of cyclosporin A : a new antilymphocytic agent. Agents and Actions 6, 468475.

Bose, A. J., Das, K. G., Funke, P. T., Kugajevsky, I., Shukla, O. P., Khanchandani, K. S. \& SuhadolNIK, R. J. (1968). Biosynthetic studies on gliotoxin using stable isotopes and mass spectral methods. Journal of the American Chemical Society 90, 10381041.

Eichner, R. D. \& MÜllbacher, A. (1984). Fungal toxins are involved in aspergillosis and AIDS. Australian Journal of Experimental Biology and Medical Science 62, 479-484.

Howard, D. H. (1983). Fungi Pathogenic for Humans and Animals. Part B. Pathogenicity and Detection. New York; Marcel Dekker.

GrinNEL, F. (1978). Cellular adhesiveness and extracellular substrata. International Reviews of Cytology 53, 65-144.

McCowen, M. C., Callender, M. E. \& Lawlis, J. F. (1951). Fumagillin (H-3), a new antibiotic with amebicidal properties. Science 113, 202-203.

MüllbaCheR, A. \& EICHNER, R. D. (1984). Immunosuppression in vitro by a metabolite of a human pathogenic fungus. Proceedings of the National Academy of Sciences of the United States of America 81, 3835-3837.

Müllbacher, A., Parish, C. R. \& Mundy, J. P. (1984). An improved colorimetric assay for $T$ cell cytotoxicity in vitro. Journal of Immunological Methods 68, 205-215.

Pang, T. \& Blanden, R. V. (1976). The role of adherent cells in the secondary cell mediated response in vitro to a natural poxvirus pathogen. Australian Journal of Experimental Biology and Medical Science 54, 559-571.

Persson, K., Hammarström, L., Möller, G. \& SMith, C. I. E. (1978). The role of adherent cells in B and T lymphocyte activation. Immunological Reviews 40, 78-101.

RaPer, J. \& FenNell, D. I. (1965). In The Genus Aspergillus, pp. 238-268. Baltimore: Williams and Wilkins.

Rippon, J. W. (1974). Medical Mycology. The Pathogenic Fungi and the Pathogenic Actinomycetes. Philadelphia, London \& Toronto: W. D. Saunders.

Starzl, T. E. (1983). Clinical aspects of cyclosporine therapy: a summation. Transplantation Proceedings XV, 3103-3107.

TAYLOR, A. (1971). The toxicology of sporidesmins and other epipolythiadioxopiperazines. In Microbial Toxins VII, pp. 337-376. Edited by S. Kadis, A. Ciegler \& S. J. Ajl. New York: Academic Press.

WILSON, B. J. (1971). Miscellaneous Aspergillus toxins. In Microbial Toxins VI, pp. 208-295. Edited by A Ciegler, S. Kadis \& S. J. Ajl. New York: Academic Press.

Yahara, I., Harada, F., Sekita, S., Yoshihira, K. \& NATORI, S. (1982). Correlation between effects of 24 different cytochalasins on cellular structures and cellular events and those on actin in vitro. Journal of Cell Biology 92, 69-78. 